\title{
Vitrac - Château de Montfort, La Garenne
}

$n^{\circ} 026111$

\section{Nadine Beague}

\section{(2) OpenEdition}

\section{Journals}

Édition électronique

URL : http://journals.openedition.org/adlfi/16487

ISSN : 2114-0502

Éditeur

Ministère de la culture

Référence électronique

Nadine Beague, «Vitrac - Château de Montfort, La Garenne », ADLFI. Archéologie de la France -

Informations [En ligne], Aquitaine, mis en ligne le 10 février 2016, consulté le 19 avril 2019. URL : http:// journals.openedition.org/adlfi/16487

Ce document a été généré automatiquement le 19 avril 2019

(C) Ministère de la Culture et de la Communication, CNRS 


\title{
Vitrac - Château de Montfort, La Garenne
}

$n^{\circ} 026111$

\author{
Nadine Beague
}

Lien Atlas (MCC) :

http://atlas.patrimoines.culture.fr/atlas/trunk/index.php?

ap_theme=DOM_2.01.02\&ap_bbox=-1.191;44.822;1.260;44.868

1 Le diagnostic a porté sur l'emprise d'un bassin de collecte des eaux pluviales en bordure de falaise dans un premier temps. En dehors de la présence d'un dépotoir récent, une érosion du substrat rocheux et un remblaiement naturel y ont été observés, mêlant quelques artefacts de toutes les époques.

2 Le diagnostic a, dans un deuxième temps, essentiellement porté sur la place allongée située en pied de rempart, où des bâtiments se trouvaient encore au début du XIX ${ }^{e} \mathrm{~s}$. La taille et l'aménagement de la roche calcaire en terrasses successives y sont mis en évidence, de même que des fondations de murs s'y appuyant, correspondant de toute évidence au bâti visible sur le cadastre napoléonien. L'ensemble du bâti semble plus ou moins contemporain des habitations subsistant sur la terrasse inférieure, soit au plus tôt $\mathrm{du} \mathrm{xvI}^{\mathrm{e}} \mathrm{s}$. Deux monnaies témoignent d'une occupation allant jusqu'au $\mathrm{xvIII}^{\mathrm{e}} \mathrm{s}$. et d'un abandon progressif au $\mathrm{XIX}^{\mathrm{e}} \mathrm{s}$. Les aménagements de terrasses au pied de l'enceinte du château, en contrebas de l'accès actuel, sont plus difficiles à appréhender, notamment en raison de la réutilisation de très grosses pierres de taille, vraisemblablement récupérées lors d'une des reconstructions du château.

3 L'espace où sont situés les sondages est une placette allongée dans le sens nord-sud. Il est évident que l'espace compris entre le premier mur d'enceinte et l'enceinte basse doublant l'enceinte principale, était dès les premiers temps taillé dans la roche pour y ménager une lice, constituant une sorte de plate-forme. L'hypothèse la plus probable est que la lice 
était laissée telle quelle puisque le remblai de grosses pierres (US 20) est manifestement moderne.

4 Le mur M2 du sondage 3 est vraisemblablement la suite du mur qui cernait complètement le château jusqu'au début du XIX ${ }^{\mathrm{e}} \mathrm{s}$. Les deux tronçons de mur reconnus dans le sondage 3 (M1 et M2) se situent à l'endroit où un passage figure en pointillé sur le cadastre napoléonien de ce qui sera plus tard l'entrée du château telle que nous la connaissons. Ce passage devait être constitué en terrasse avec des marches taillées dans la roche et des pierres pour retenir la terre. Dans ce cas, ce que nous soupçonnions pour M1, à savoir une ouverture dans un muret de terrasse par la suite rebouchée, est conforme à ce que nous indique le cadastre ancien.

INDEX

Mots-clés : bâti, lice

Index chronologique : ép. contemporaine, Temps Modernes

Index géographique : Aquitaine, Dordogne (24), Vitrac

operation Opération préventive de diagnostic (OPD)

\section{AUTEURS}

NADINE BEAGUE

Inrap 